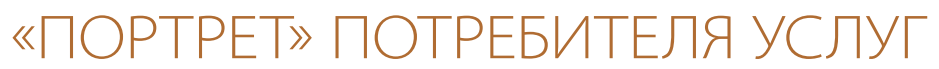

\title{
ДИСТАНЦИОННОГО ОБУЧЕНИЯ
}

В УСЛОВИЯХ РЕАЛИЗАЦИИ

НЕФОРМАЛЬНОГО ОБРАЗОВАНИЯ ДЕТЕЙ

\section{"PORTRAIT" OF THE RECEIVER OF DISTANCE LEARNING SERVICES IN THE CONTEXT OF IMPLEMENTATION OF NON-FORMAL EDUCATION OF CHILDREN}

\section{Бабич Любовь Васильевна}

Заместитель директора по научной работе, заведующий отделом исследований влияния интеграционных процессов в науке и образовании на территориальное развитие, Вологодский научный центр Российской академии наук, кандидат экономических наук E-mail: lvbabich@vscc.ac.ru

\section{Мироненко Елена Станиславовна}

Старший научный сотрудник отдела исследований влияния интеграционных процессов в науке и образовании на территориальное развитие, Вологодский научный центр Российской академии наук, кандидат филологических наук

E-mail: voselena35@mail.ru

\section{Рыбичева Ольга Юрьевна}

Младший научный сотрудник отдела исследований влияния интеграционных

\begin{abstract}
Babich Lyubov V.
Deputy Director for Research, Head of the Department of Research into the Influence of Integration Processes in Science and Education on the Territorial Development, Vologda Scientific Center of the Russian Academy of Sciences, PhD in Economics

E-mail: Ivbabich@vscc.ac.ru
\end{abstract}

\section{Mironenko Elena S.}

Senior Research Fellow at the Department of Research into the Influence of Integration Processes in Science and Education on the Territorial Development, Vologda Scientific Center of the Russian Academy of Sciences, Vologda, PhD in Linguistics

E-mail:voselena35@mail.ru

\section{Rybicheva Olga Yu.}

Junior Research Fellow at the Department of Research of the Influence of Integration

(C) Бабич Л. В., Мироненко Е. С., Рыбичева О. Ю., 2020 
процессов в науке и образовании на территориальное развитие, Вологодский научный центр Российской академии наук E-mail: garmanova@yandex.ru

Аннотация. Цель статьи состояла в проведении комплексного исследования детей как потребителей услуг дистанционного обучения для организации в дальнейшем личностно ориентированного образовательного процесса, способствующего достижению более высоких результатов. В свете этого авторами в 2018 г. были проведены опросы среди обучающихся Экономической интернет-школы Вологодского научного центра Российской академии наук. Была предпринята попытка комплексного изучения характеристик потребителей данных услуг, таких как: демографические особенности, уровень мотивации, статус личностного развития, коммуникативные и организаторские особенности. Кроме того, проанализировано влияние данных факторов на успехи в учебе. Таким образом, был составлен «портрет» обучающегося с целью эффективной организации образовательного процесса. Исходя из результатов исследования, были внесены предложения, касающиеся организации дистанционного обучения детей.

Ключевые слова: неформальное образование, дистанционное обучение детей, онлайнобразование, потребители образовательных услуг.

\section{Processes in Science and Education on the Territorial Development, Vologda Scientific Center of the Russian Academy of Sciences, Vologda \\ E-mail: garmanova@yandex.ru}

\begin{abstract}
The goal of the research was to conduct a comprehensive study of children as receivers of distance learning services in order to organize in the future a studentcentered educational process that contributes to the achievement of better results. In 2018, the authors conducted surveys among students at the Economic Internet School of the Vologda Scientific Center of the Russian Academy of Sciences. The characteristics of receivers of such services as demographic characteristics, level of motivation, status of personal development, communication and organizational features, were comprehensively studied. In addition, the effect of these factors on learning success was analyzed. Thus, the "portrait" of the student was compiled with the goal to effectively organize the educational process. Based on the results of the study, we make suggestions concerning the organization of distance learning for children.
\end{abstract}

Keywords: non-formal education, children's distance learning, online education, educational services receivers.

В современном обществе человек является ядром социально-экономической системы, а человеческий капитал - ключевым ресурсом и главным конкурентным преимуществом. Встает вопрос о качестве человеческого капитала, накопление которого происходит в большей степени через систему образования. Однако в настоящее время школа, как начальный уровень этой системы, ориентированный на формирование у обучающихся базовых знаний и навыков, необходимых для жизни в быстроменяющемся мире и дальнейшей профессиональной подготовки, потеряла монополию на передачу подрастающему 
поколению культурных ценностей и нужных для продуктивной жизни сведений. Не отвечает современным вызовам и сфера дополнительного образования, направленная на углубленное погружение обучающихся в различные предметные области. Как отмечают исследователи, «одна из серьезных проблем современной российской школы и дополнительного образования - растущее отставание от требований цифровизации экономики и основных сфер общественной жизни»1.

Невозможность официальных систем образования дать быстрый ответ на социально-экономические изменения в обществе стала предметом дискуссии на международной конференции в Уильямсберге (США) еще в 1967 г. Тогда впервые заговорили о возрастающем «мировом кризисе в сфере образования» [1]. Решение вопроса виделось в потенциале системы неформального образования.

Формальное, неформальное и информальное образование являются «составляющими непрерывного образования» [2, с. 182]. Неформальное образование детей - «часть общего образования, позволяющая учащемуся приобрести устойчивую потребность в познании и творчестве, максимально реализовать себя, самоопределиться профессионально и личностно» [2, с. 182].

В данной работе мы остановимся на дистанционном обучении детей как одной из форм неформального образования, связанной с использованием информационных технологий, независимо от того, где протекает процесс обучения. Следует отметить, что актуальности применения дистанционного обучения при организации образовательного процесса взрослых и детей посвящены многочисленные работы зарубежных и отечественных ученых. В большинстве из них акцентируется внимание на вопросе эффективности обучения, а также мотивации и качества дистанционного образования.

Соглашаясь с Л. С. Райнтзема, отметим, что эффективность процесса обучения, в том числе дистанционного, во многом определяется особенностями конкретных потребителей тех или иных образовательных услуг [3]. От движимых ими целей, мотивов обучения, склонностей, места жительства и технических возможностей зависит не только их успех обучения на расстоянии, но и результативность всей системы подготовки. В этой связи важным представляется тезис о том, что для максимального удовлетворения образовательных потребностей необходимо установить ожидаемые и предположить неожидаемые потребности конкретных потребителей [4]. Проведение данного исследования предполагает составление «портрета» потребителей услуг дистанционного обучения, выявление типичных характеристик, которые необходимо учитывать при организации образовательного процесса.

В зарубежной литературе, как правило, исследователи делают акцент на изучении удовлетворенности слушателей онлайн-обучением [5; 6], а также на выявлении у них мотивов к обучению дистанционно [7; 8]. Существующие исследования мотивации в онлайнсреде, как правило, используют один из двух подходов. Первый применяет модель, которая рассматривает мотивацию как относительно стабильную личностную характеристику

1 Двенадцать решений для нового образования: доклад Центра стратегических разработок и Высшей школы экономики. М., 2018. С. 30. 
обучающегося. Исследования с этой точки зрения привели к пониманию того, что обучающиеся дистанционно в целом мотивированы [9]. Альтернативный подход концентрируется на дизайне сред, чтобы стимулировать оптимальную мотивацию обучающегося в онлайн-среде [10; 11]. Данные последних исследований свидетельствуют о том, что проектирование онлайн-курса, а также преподаватель, его общение с обучающимися являются самыми сильными факторами, влияющими на их удовлетворенность онлайн-курсом и успех обучения [12].

Резюмируя выводы зарубежных исследований, можно выделить следующие факторы, оказывающие влияние на успешность дистанционного обучения: демографические характеристики, место жительства, мотивы обучения.

Отечественные исследователи, так же, как и зарубежные, акцентируют внимание на изучении удовлетворенности слушателей дистанционном обучением, учебных мотивов и факторов, оказывающих влияние на эффективность обучения на расстоянии.

Авторы анализируют половозрастные особенности слушателей онлайн-курсов, характер их занятости, причины участия в курсах, отзывы и результаты дистанционного обучения [13].

Обобщая выводы зарубежных и отечественных исследователей отметим, что для эффективной организации дистанционного обучения необходимо учитывать половозрастной состав, место жительства обучающихся, мотивы их обучения, коммуникативные и организаторские склонности как критерии, позволяющие оценить способности школьников к общению и самоорганизации, результаты обучения. В связи с этим важным представляется проведение комплексного исследования детей как потребителей услуг дистанционного обучения для организации в дальнейшем личностно ориентированного образовательного процесса, способствующего достижению более высоких результатов.

Комплексное исследование потребителей услуг дистанционного обучения проводилось в 2017/18 учебном году на базе Экономической интернет-школы Федерального государственного бюджетного учреждения науки «Вологодский научный центр Российской академии наук» (Экономическая интернет-школа, ВолНЦ РАН). Она была создана при ВолНЦ РАН в 2010 г. с целью организации дистанционного обучения по основам экономики для обучающихся основных и средних общеобразовательных учреждений.

За время работы Экономической интернет-школы в удаленный образовательный процесс было вовлечено более 1100 обучающихся 8-11-х классов из различных регионов Российской Федерации и Республики Беларусь. Из них значительная часть обучающихся, успешно завершив курс обучения, получила сертификат о прохождении дистанционного курса. Информационной площадкой для организации дистанционного обучения выступает сайт Экономической интернет-школы (http://moodle.vscc.ac.ru/), созданный на основе свободно распространяемого программного обеспечения Moodle. На нем размещены четыре (8-11-й классы) открытых учебных курса, которые разработаны с учетом ФГОС профильного школьного экономического образования. Учебный материал в каждом из них сформирован в 8 тематических разделов, состоящих из лекций, презентаций, примеров решения задач, упражнений, тестов, контрольных работ, а также итоговой контрольной работы и тестирования. На изучение каждой темы школьникам отводится один месяц 
(обучение длится с 1 сентября по 30 апреля), на выполнение итоговых заданий - 15 дней (их необходимо решить в период с 1 по 15 мая).

Для обеспечения эффективного взаимодействия с обучающимися в Экономической интернет-школе действует система тьюторства. Она включает в себя оказание помощи и поддержки обучающимся педагогом-тьютором, координирующим деятельность Экономической интернет-школы, и кураторами учащихся в школе.

Оценка деятельности обучающихся на сайте Экономической интернет-школы осуществляется с помощью балльно-рейтинговой системы. Результаты ее ежемесячно доводятся до школьников и курирующих их преподавателей в образовательных организациях.

Проведенное нами на базе Экономической интернет-школы исследование потребителей услуг дистанционного обучения включало в себя анализ следующих особенностей обучающихся:

- половозрастной состав;

- место жительства;

- результаты обучения (на основе мониторинга успеваемости обучающихся, регулярно проводимого в Экономической интернет-школе, а также анкетирования школьников об удовлетворенности дистанционным обучением, состоящего из 17 вопросов открытого и закрытого типа);

- мотивы учебной деятельности (по методике А. А. Реана и В. А. Якунина, позволяющей выявить у обучающихся из 16 предложенных мотивов до пяти наиболее значимых мотивов учебной деятельности);

- учебная мотивация (по методике диагностики мотивации учения и эмоционального отношения к учению в средних и старших классах Ч. Д. Спилберга (модификация А. Д. Андреевой), позволяющей с помощью 40 утверждений диагностировать у обучающихся различные уровни учебной мотивации: от первого, характеризующегося продуктивной мотивацией с выраженным преобладанием познавательной мотивации учения и положительным эмоциональным отношением к нему, до пятого, отличающегося резким отрицательным отношением к учению);

- коммуникативные и организаторские склонности (с помощью тест-опросника «Коммуникативные и организаторские склонности (КОС-2)» В. В. Синявского и Б. А. Федоришина, позволяющего на основе 40 вопросов выявить у обучающихся различные уровни коммуникативных и организаторских склонностей: от очень низкого, свидетельствующего о крайне низких способностях к общению и самоорганизации, до высшего, характеризующегося сформированной потребностью в коммуникативной и организаторской деятельности, способностью быстро ориентироваться в трудных ситуациях, принятии самостоятельных решений, отстаиванием своего мнения и др.).

При изучении половозрастного состава, места жительства обучающихся, реальных результатов обучения школьников анализировалась информация по всем 160 учащимся, занимающимся в 2017/18 учебном году в Экономической интернет-школе. Исследование мотивов учебной деятельности, учебной мотивации, коммуникативных и организаторских склонностей, результатов обучения проводилось на основе анкетирования, в котором приняли участие 90 обучающихся. 
Половозрастной состав. Потребителями услуг дистанционного обучения в Экономической интернет-школе являются в основном девушки (60,6\%). 39,4\% потребителей услуг дистанционного обучения - юноши.

Возрастной состав обучающихся следующий:

29,4\% - школьники в возрасте 14 лет, занимающиеся по курсу 8-го класса;

11,9\% - школьники в возрасте 15 лет, проходящие курс 9-го класса;

46,2\% - школьники в возрасте 16-17 лет, занимающиеся по курсу 10-го класса;

12,5\% - школьники в возрасте 17-18 лет, проходящие курс 11-го класса.

Для данных возрастных групп ведущей является полезная, социально значимая и учебно-профессиональная деятельность, в процессе которой у подростков формируются мировоззрение, профессиональные интересы, самосознание и идеалы. Это в значительной степени объясняет изменения в возрастной структуре обучающихся Экономической интернет-школы. Школьники 14, 16-17 лет, определяющиеся с направлением своей будущей профессиональной деятельности, а также желающие расширить свой кругозор в области экономики, массово проходят дистанционную подготовку. Школьники 15, 17-18 лет, выбравшие экономику, скорее всего, как одну из приоритетных сфер, осознанно изучают предложенный учебный материал. В целом следует отметить, что для всех обучающихся, вовлеченных в образовательный процесс, прохождение дистанционных курсов носит профориентационную направленность.

Место жительства. Большая часть (96,3\%) потребителей услуг дистанционного обучения Экономической интернет-школы проживает в городской местности. Доля обучающихся из сельских территорий составляет лишь 3,7\% от общего количества школьников (жители поселков Вожега и Фетинино Вологодской области). Данные различия можно объяснить тем, что «...мотивация учения, познавательные интересы сельских школьников развиты значительно слабее, чем городских».

Следует отметить, что большая часть городских жителей $(61,2 \%)$ в структуре обучающихся представлена школьниками, проживающими в средних по численности населения городах России (Старая Русса, Кинешма, Мончегорск) и Республики Беларусь (Слоним). 35,1\% потребителей услуг дистанционного обучения - это жители крупных городов РФ (Петрозаводск, Волгодонск, Калуга, Ярославль).

Более высокий спрос на обучение в Экономической интернет-школе у обучающихся из средних городов обусловлен прежде всего ограниченными возможностями приобретения экономических знаний в муниципальных учреждениях дополнительного образования детей. Как отмечают исследователи, именно сфера дополнительного образования располагает существенным потенциалом для развития детей; формирования у них навыков XXI в.: критического мышления, креативности, коммуникабельности и способности работать в команде. Она же характеризуется и существенными территориальными различиями. Так, в средних городах и сельской местности меньше, чем в крупных городах, организаций, оказывающих дополнительные образовательные услуги для детей, у'же предложение и, следовательно, меньше выбор программ. Данные отличия были выявлены нами в результате выборочного обследования количества учреждений дополнительного образования детей в населенных пунктах, из которых были набраны школьники, а также численности 
посещающих их детей и реализуемых направлений подготовки. Эти различия отмечаются в работах ряда отечественных ученых [13], подтверждаются данными федеральных статистических наблюдений. Так, например, в 2017 г. в городских поселениях России функционировали 37399 учреждений, осуществляющих образовательную деятельность по дополнительным образовательным программам для детей, а в сельской - только 18903 организации².

Территориальные различия в особенностях организации подготовки школьников по отдельным предметам менее выражены в учреждениях общего образования. В частности, экономика в современной школе вне зависимости от места проживания обучающихся углубленно изучается лишь в профильных (социально-экономических) классах или в рамках специальных факультативных курсов. Обучающиеся других профилей и те, кто не посещает такие занятия, осваивают ее фрагментарно в рамках курсов обществознания, географии, истории. Следовательно, возможность получения глубоких знаний по экономике в школьном возрасте зависит от выбора учебного заведения и профиля обучения.

Таким образом, доминирование в структуре обучающихся Экономической интернет-школы учеников из средних городов связано с отсутствием или ограниченным количеством мест в учреждениях дополнительного образования детей по данному направлению подготовки, обучением по другому профилю в школе.

География обучающихся Экономической интернет-школы в основном представлена регионами Северо-Западного федерального округа: Новгородской (50,6\%), Вологодской (3,7\%), Мурманской $(1,9 \%)$ областями и Республикой Карелия $(19,4 \%)$. Часть обучающихся проживает в Южном (Ростовская область - 12,5\%) и Центральном (Ивановская область - 3,7\%, Калужская область - 1,9, и Ярославская область - 1,3\%) федеральных округах, Республике Беларусь (Гродненская область, г. Слоним - 5\%). Наиболее востребованным дистанционное обучение в Экономической интернет-школе было у обучающихся из Северо-Западного федерального округа.

Рассматривая недостаточное разнообразие программ в учреждениях дополнительного образования детей в качестве одного из факторов выбора дистанционного обучения школьниками, остановимся на количественных показателях развития системы дополнительного образования детей в разрезе рассматриваемых федеральных округов. В СевероЗападном округе количество организаций, осуществляющих образовательную деятельность по дополнительным общеобразовательным программам для детей, и количество учащихся, занимающихся в них, значительно меньше, чем в Южном и Центральном федеральных округах (табл. 1). Приведенные данные еще раз наглядно показывают неравномерность развития рынка дополнительных образовательных услуг и потребность школьников в альтернативных вариантах для своего развития.

Таким образом, потребителями услуг дистанционного обучения в Экономической интернет-школе являются подростки Северо-Западного, Южного, Центрального федерального округов России и из Республики Беларусь, проживающие в городской и сельской местности с различным уровнем развития индустрии дополнительного образования детей.

2 Данные приведены с сайта Федеральной службы государственной статистики: http://www.gks.ru/ free_doc/new_site/population/obraz/dop-obraz.htm). 
Таблица 1

Показатели, характеризующие состояние системы дополнительного образования детей в регионах России в 2017 г.

\begin{tabular}{|c|c|c|c|c|c|c|}
\hline \multirow[t]{2}{*}{ Регион } & \multicolumn{3}{|c|}{$\begin{array}{c}\text { Количество организаций, осу- } \\
\text { ществляющих образовательную } \\
\text { деятельность по дополнитель- } \\
\text { ным общеобразовательным про- } \\
\text { граммам для детей, ед. }\end{array}$} & \multicolumn{3}{|c|}{$\begin{array}{l}\text { Количество учащихся, занимаю- } \\
\text { щихся по дополнительным обще- } \\
\text { образовательным программам, чел. }\end{array}$} \\
\hline & Всего & $\begin{array}{c}\text { В городах } \\
\text { и поселках } \\
\text { городского } \\
\text { типа } \\
\end{array}$ & $\begin{array}{l}\text { В сельской } \\
\text { местности }\end{array}$ & Всего & $\begin{array}{c}\text { В городах } \\
\text { и поселках } \\
\text { городского } \\
\text { типа } \\
\end{array}$ & $\begin{array}{l}\text { В сель- } \\
\text { ской } \\
\text { местно- } \\
\text { сти }\end{array}$ \\
\hline \multicolumn{7}{|c|}{ Северо-Западный федеральный округ } \\
\hline Всего по СЗФО & 5084 & 4010 & 1074 & 2355894 & 2147473 & 208421 \\
\hline Новгородская область & 434 & 281 & 153 & 106381 & 92731 & 13650 \\
\hline Республика Карелия & 231 & 176 & 55 & 105402 & 97944 & 7458 \\
\hline Вологодская область & 695 & 476 & 219 & 221098 & 178309 & 42789 \\
\hline Мурманская область & 362 & 330 & 32 & 131874 & 126552 & 5322 \\
\hline \multicolumn{7}{|c|}{ Южный федеральный округ } \\
\hline Всего по ЮФО & 6240 & 3597 & 2643 & 2446371 & 1696911 & 749460 \\
\hline Ростовская область & 1619 & 863 & 756 & 711203 & 493401 & 217802 \\
\hline \multicolumn{7}{|c|}{ Центральный федеральный округ } \\
\hline Всего по ЦФО & 13773 & 9665 & 4108 & 7913067 & 7228958 & 684109 \\
\hline Ивановская область & 437 & 333 & 104 & 173458 & 160051 & 13407 \\
\hline Калужская область & 376 & 255 & 121 & 134126 & 116705 & 17421 \\
\hline Ярославская область & 433 & 363 & 70 & 202092 & 179600 & 22492 \\
\hline
\end{tabular}

Составлено авторами по данным сайта Федеральной службы государственной статистики. Режим доступа: http://www.gks.ru/free_doc/new_site/population/obraz/dop-obraz.htm

Мотивы обучения. Потребители услуг дистанционного обучения в Экономической интернет-школе - это ученики, осознающие роль обучения в их жизни. Об этом свидетельствуют результаты проведенных нами диагностик. Так, в соответствии с методикой А. А. Реана и В. А. Якунина обучающиеся из 16 предложенных мотивов к учебной деятельности к наиболее значимым мотивам отнесли следующие: «Обеспечить успешность будущей профессиональной деятельности», «Успешно учиться, сдать экзамены на “хорошо" и "отлично"», «Стать высококвалифицированным специалистом», «Приобрести глубокие и прочные знания», «Получить интеллектуальное удовлетворение». Это говорит о том, что они нацелены не только на личностное развитие и профессиональное становление, но и на получение удовлетворения от процесса обучения. Наименее значимы для обучающихся мотивы «Избежать осуждения и наказания за плохую учебу» и «Выполнять педагогические требования» (табл. 2). Это подтверждает нашу точку зрения и мнение ряда авторов о малой эффективности для современной молодежи, особенно в условиях дистанционного обучения, системы воспитания через общественное поощрение/порицание. 
Распределение мотивов учебной деятельности обучающихся Экономической интернет-школы (по методике А.А. Реана и В.А. Якунина), \%

\begin{tabular}{|l|l|c|}
\hline № & \multicolumn{1}{|c|}{ Мотив } & Доля выбравших \\
\hline 1 & Обеспечить успешность будущей профессиональной деятельности & 82,9 \\
\hline 2 & Успешно учиться, сдать экзамены на «хорошо» и «отлично» & 80,5 \\
\hline 3 & Стать высококвалифицированным специалистом & 65,9 \\
\hline 4 & Приобрести глубокие и прочные знания & 61,0 \\
\hline 5 & Получить интеллектуальное удовлетворение & 51,2 \\
\hline 6 & Получить диплом & 46,3 \\
\hline 7 & Достичь уважения преподавателей & 31,7 \\
\hline 8 & Быть постоянно готовым к очередным занятиям & 31,7 \\
\hline 9 & Успешно продолжить обучение на последующих курсах & 29,3 \\
\hline 10 & Добиться одобрения родителей и окружающих & 26,8 \\
\hline 11 & Не запускать предметы учебного цикла & 26,8 \\
\hline 12 & Постоянно получать стипендию & 26,8 \\
\hline 13 & Быть примером сокурсникам & 22,0 \\
\hline 14 & Не отставать от сокурсников & 19,5 \\
\hline 15 & Избежать осуждения и наказания за плохую учебу & 17,1 \\
\hline 16 & Выполнять педагогические требования & 12,2 \\
\hline
\end{tabular}

Заинтересованность обучающихся в получении образовательных услуг подтверждается также методикой диагностики мотивации учения и эмоционального отношения к учению в средних и старших классах Ч. Д. Спилберга (модификация А. Д. Андреевой). Использование ее позволило выявить преобладание у обучающихся Экономической интернет-школы продуктивной (2 уровень) и средней (3 уровень) мотивации учения (табл. 3). Продуктивная мотивация с позитивным отношением школьников к учебе, соответствующая социальному нормативу, была диагностирована у 43\% опрошенных школьников. Средний уровень, с несколько сниженной познавательной мотивацией, был выявлен у 45\% удаленных обучающихся.

Как и при очном обучении, небольшую долю в общем числе всех опрошенных составляли школьники с продуктивной познавательной мотивацией и положительным эмоциональным отношением к учению (3\%; 1-й уровень) и со сниженной мотивацией, переживанием «школьной скуки», отрицательным эмоциональным отношением к учению $(9 \%$; 4-й уровень). Следует отметить, что обучающихся с резко отрицательным отношением к учению выявлено не было.

Следовательно, потребителями услуг дистанционного обучения в Экономической интернет-школе являются подростки, заинтересованные в своем развитии и самореализации. Вместе с тем у значительной части обучающихся наблюдается средний уровень с несколько сниженной познавательной мотивацией и сниженная мотивация с отрицательным отношением к учению. Это, на наш взгляд, требует особого внимания преподавателей к данной категории школьников: проведения дополнительных исследований, 
Диагностированные уровни мотивации учения у обучающихся Экономической интернет-школы (по методике диагностики мотивации учения и эмоционального отношения к учению в средних и старших классах Ч. Д. Спилберга), \%

\begin{tabular}{|c|l|c|}
\hline Уровень & \multicolumn{1}{|c|}{ Краткая характеристика } & Доля обучающихся \\
\hline 1-й уровень & $\begin{array}{l}\text { Продуктивная мотивация с преобладанием познавательной мо- } \\
\text { тивации, положительным эмоциональным отношением к учению }\end{array}$ & 3 \\
\hline 2-й уровень & Продуктивная мотивация, позитивное отношение к учению & 43 \\
\hline 3-й уровень & $\begin{array}{l}\text { Средний уровень с несколько сниженной познавательной моти- } \\
\text { вацией }\end{array}$ & 9 \\
\hline 4-й уровень & $\begin{array}{l}\text { Сниженная мотивация, переживание «школьной скуки», отрица- } \\
\text { тельное эмоциональное отношение к учению }\end{array}$ \\
\hline
\end{tabular}

позволяющих выяснить причины отрицательного эмоционального отношения к учебе, более тщательного построения индивидуального образовательного маршрута для таких обучающихся, организации развивающей и корректирующей работы с ними.

Коммуникативные и организаторские склонности. Большинство потребителей услуг дистанционного обучения Экономической интернет-школы обладает достаточным (а именно средним, высоким или высшим) уровнем коммуникативных и организаторских склонностей. Он диагностировался с помощью теста-опросника «Коммуникативные и организаторские склонности (КОС-2)» В. В. Синявского и Б. А. Федоришина. Так, судя по результатам проведенного нами исследования, достаточного уровня коммуникативных склонностей достигли 58\% опрошенных школьников (из них средний уровень был выявлен у 28\%, высокий - у 25\%, высший - у 5\%), достаточного уровня организаторских склонностей - 81\% обучающихся (из которых средний уровень диагностирован у 33\%, высокий у $38 \%$, высший у - 10\%).

Остальные опрошенные не обладают достаточным уровнем склонностей, как коммуникативных (42\%: из них низкий уровень у 32\% школьников, очень низкий - у 10\%), так и организаторских (19\%: низкий уровень у 17\%, очень низкий - у 2\%; табл. 4). Они, согласно используемой методике, не стремятся к общению, испытывают трудности в установлении контактов с людьми, не отстаивают своего мнения, тяжело переживают обиды, редко проявляют инициативу, избегают принятия самостоятельных решений.

В целом следует отметить, что большинство потребителей услуг дистанционного обучения Экономической интернет-школы обладают достаточным уровнем коммуникативных и организаторских склонностей. Часть не достигших его школьников имеют трудности с общением и саморганизацией. Поскольку данные особенности потребителей могут влиять на результативность дистанционного обучения, они должны учитываться при организации образовательного процесса. В частности, необходима реализация мероприятий, стимулирующих активность школьников (онлайн-чаты, онлайн-форумы, онлайн-консультации).

Результаты обучения. Потребители услуг дистанционного обучения осознают важность экономики как науки и экономических знаний в современной жизни, ориентированы на реализацию своих учебных мотивов. Так, опрос, посвященный выявлению удовлетворенности школьников обучением в Экономической интернет-школе, подтвердил 
Уровни коммуникативных и организаторских склонностей обучающихся

Экономической интернет-школы (по результатам тест-опросника «Коммуникативные и организаторские склонности» В. В. Синявского

и Б. А. Федоришина), \%

\begin{tabular}{|l|c|c|c|c|c|}
\hline \multirow{2}{*}{\multicolumn{1}{|c|}{ Склонности }} & \multicolumn{5}{|c|}{ Уровень } \\
\cline { 2 - 6 } & Высший & Высокий & Средний & Низкий & Очень низкий \\
\hline Коммуникативные & 5 & 25 & 28 & 32 & 10 \\
\hline Организаторские & 10 & 38 & 33 & 17 & 2 \\
\hline
\end{tabular}

профессиональную направленность их подготовки и стремление к получению интеллектуального удовлетворения. Основными целями обучения участники опроса считают углубление знаний в области экономики (76,7\%) и расширение кругозора (66,7\%). Они ориентированы также на выяснение сущности основных экономических понятий $(44,4 \%)$ и подготовку к поступлению на экономические факультеты вузов (33,3\%; табл. 5). Немаловажными для детей и, скорее всего, их родителей является возможность получения бесплатного образования (38,9\%) и расширения круга общения $(10 \%)$.

Дистанционное обучение в Экономической интернет-школе способствовало достижению поставленных целей для большинства участников исследования. Об этом свидетельствуют результаты их успеваемости по итогам года и исследования удовлетворенности дистанционным обучением.

Так, в соответствии с внедренной в Экономической интернет-школе балльно-рейтинговой системой, доля успевающих на «отлично» составляла 18,1\% в общем числе опрошенных, на «хорошо» - 20\%, на «удовлетворительно» - 24,4\%. Были не аттестованы 37,5\% обследованных школьников. Учитывая углубленный уровень курсов, подчеркнем, что на «отлично» оценивались учащиеся, набравшие по итогам учебного года 70-100\% баллов от максимально возможного количества, на «хорошо» - 50-69\% баллов, на «удовлетворительно» - 30-49\% баллов. Школьники с меньшим количеством баллов не аттестовывались. Достижению данных показателей успеваемости способствовала система тьюторства.

Сами обучающиеся высоко оценили уровень получаемых в Экономической интернет-школе знаний и умений. В рамках опроса, посвященного оценке удовлетворенности

Таблица 5

Распределение ответов на вопрос «Каковы цели вашего обучения в Экономической интернет-школе?», \%

\begin{tabular}{|l|c|}
\hline \multicolumn{1}{|c|}{ Цели обучения } & Доля выбравших \\
\hline 1. Углубить свои знания в области экономики & 76,7 \\
\hline 2. Расширить кругозор & 66,7 \\
\hline 3. Выяснить сущность основных экономических понятий & 44,4 \\
\hline 4. Получить бесплатное образование & 38,9 \\
\hline 5. Подготовиться к поступлению на экономический факультет & 33,3 \\
\hline 6. Расширить круг общения & 10,0 \\
\hline
\end{tabular}


дистанционным обучением, его участники отмечали формирование у них знаний в области экономики (80\%), навыков самоорганизации (57,8\%), умений искать альтернативные подходы к решению проблемы (53,3\%), умений достигать поставленных задач $(43,3)$, умения рационально мыслить (41,1\%), навыков планирования и проведения научно-исследовательской работы (32,2\%; табл. 6). Важно и то, что части обучающихся дистанционное обучение помогло определиться с выбором профессии (11,1\%) и найти новых друзей и знакомых $(3,3 \%)$.

Взаимосвязь между отдельными характеристиками потребителей услуг дистанционного обучения. В ходе исследования проверялись взаимосвязи между исследуемыми параметрами. Наиболее тесная взаимосвязь (при р $\leq 0,05)$ была выявлена:

- между успеваемостью школьников и их полом (коэффициент корреляции равен 0,6), женским полом $(\mathrm{R}=0,68)$;

- между успеваемостью и организаторскими склонностями обучающихся $(\mathrm{R}=0,56)$;

- между успеваемостью и коммуникативными склонностями обучающихся $(\mathrm{R}=0,54)$;

- между успеваемостью и мотивацией учения обучающихся $(\mathrm{R}=0,53)$.

На основании выявленных взаимосвязей можно утверждать, что при прочих равных условиях более успешными в Экономической интернет-школе являются девушки. Также можно констатировать, что высокая успеваемость обучающихся как женского, так и мужского пола напрямую связана с высокими уровнями коммуникативных, организаторских склонностей и учебной мотивации. Исходя из этого можно сделать вывод о необходимости проведения перед началом обучения диагностики мотивации учения и эмоционального отношения к учению, а также необходимости теста-опросника, направленного на выявление коммуникативных и организаторских склонностей, и построения в соответствии с результатами диагностики и тестирования индивидуального маршрута обучения школьников. Такой подход, на наш взгляд, может обеспечить более высокие результаты подготовки обучающихся.

По мере развития и совершенствования дистанционного образования необходимо переходить от количества к качеству. Онлайн-образование уже не следует рассматривать как способ привлечения все большего числа учащихся, вместо этого следует сосредоточиться на обеспечении качества.

Наше исследование позволило составить «портрет» потребителя дистанционных образовательных услуг, на которого должен ориентироваться разработчик дистанционного

Таблица 6

Распределение ответов на вопрос «Что вам дает обучение в Экономической интернет-школе?», \%

\begin{tabular}{|l|c|}
\hline \multicolumn{1}{|c|}{ Формируемые знания, умения и навыки } & Доля выбравших \\
\hline 1. Знания в области экономики & 80,0 \\
\hline 2. Навыки самоорганизации & 57,8 \\
\hline 3. Умения искать альтернативные подходы к решению проблемы & 53,3 \\
\hline 4. Умения достигать поставленных задач & 43,3 \\
\hline 5. Умение рационально мыслить & 41,1 \\
\hline 6. Навыки планирования и проведения научно-исследовательской работы & 32,2 \\
\hline
\end{tabular}


курса для детей. Таким потребителем является девушка в возрасте 16-17 лет, проживающая в среднем по численности населения городе России. Для нее базовым мотивом обучения выступает профессиональный рост, целями обучения - углубление знаний, расширение кругозора, получение диплома и приобретение специальности. При этом для нее характерна продуктивная (2-й уровень) или средняя (3-й уровень) мотивация учения. Также она обладает достаточным уровнем коммуникативных и организаторских склонностей, что способствует ее успешному обучению на расстоянии, достижению стоящих перед ней целей обучения в Экономической интернет-школе.

Мы пришли к выводу о существенных различиях в состоянии системы дополнительного образования детей в разных территориях. Результаты проведенных нами опросов могут найти применение в ходе разработки стратегии развития отдельного образовательного учреждения на рынке образовательных услуг и мероприятий по совершенствованию системы дистанционного обучения детей и подростков.

\section{Список литературы}

1. Бабаева Э. С. История неформального образования за рубежом // Гуманизация образования. 2015. № 2. С. 131-137.

2. Иванова И. В. Неформальное образование - инвестиции в человеческий капитал // Вестн. Томского гос. ун-та. Психология и педагогика. 2015. № 390. С. 179-184. DOI: https://doi.org/10.17223/15617793/390/30.

3. Райнтзема Л. С. «Портрет» слушателя программы «Обучение деловому английскому языку в условиях динамики бизнес-среды» // Вестник МГОУ. Сер.: «Педагогика». 2011. № 3. С. 217-220.

4. Гайдукова Г. Н. Социологический мониторинг удовлетворенности потребителей качеством образовательных услуг // Современные проблемы науки и образования. 2013. № 1. С. 463.

5. DivjakM., Rupel V.P., Lešnik K. M. The impact of study attitudes and study behaviour on satisfaction of online students with the implementation of online study programmes // Educational Media International. 2018. Vol. 55, Iss. 3. P. 287-300. DOI: https://doi. org/10.1080/09523987.2018.1512450.

6. Machado E. A., Afonso L. E. Academic performance of students on the grounds of their satisfaction with distance education // International Journal of Innovation and Learning (IJIL). 2018. Vol. 23, No. 2. DOI: https://doi.org/10.1504/IJIL.2018.089616.

7. Barak M., Hussein-Farraj R., Dori Y. J. On-campus or online: examining self-regulation and cognitive transfer skills in different learning settings // International Journal of Educational Technology in Higher Education. 2016. DOI: https://doi.org/10.1186/ s41239-016-0035-9.

8. Hartnett M., St. George A. \& Dron J. Examining motivation in online distance learning environments: Complex, multifaceted and situation-dependent // The International Review of Research in Open and Distributed Learning. 2011. Vol. 12, No. 6. P. 20-38.

9. Bekele T. A. Motivation and satisfaction in internet-supported learning environments: A review // Educational Technology \& Society. 2010. Vol. 13, Iss. 2. P. 116-127. 
10. McCombs B. L., Vakili D. A learner-centered framework for e-learning // Teachers College Record. 2005. Vol. 107, No. 8. P. 1582-1600.

11. Schunk D. H., Pintrich P. R., Meece J. L. Motivation in education (3rd ed.). Upper Saddle River, NJ: Pearson Merrill Prentice Hall, 2008.

12. Eom S. B., Ashill N. The Determinants of Students' Perceived Learning Outcomes and Satisfaction in University Online Education: An Update // Decision Sciences Journal of Innovative Education. 2016. Vol. 14, Iss. 2. P. 185-215. DOI: https://doi.org/10.1111/ dsji.12097.

13. Абабкољ Ю. Н., АбабкоЪ М. Ю. Маркетинговые исследования потребителей образовательных услуг // Теория и практика сервиса: экономика, социальная сфера, технологии. 2010. № 2 (4). С. 96-102.

\section{References}

1. Babaeva E. S. Istoriya neformalnogo obrazovaniya za rubezhom. Gumanizatsiya obrazovaniya. 2015, No. 2, pp. 131-137.

2. Ivanova I. V. Neformalnoe obrazovanie - investitsii v chelovecheskiy capital. Vestn. Tomskogo gos. un-ta. Psikhologiya i pedagogika. 2015, No. 390, pp. 179-184. DOI: https:// doi.org/10.17223/15617793/390/30.

3. Rayntzema L.S. "Portret” slushatelya programmy "Obuchenie delovomu angliyskomu yazyku v usloviyakh dinamiki biznes-sredy". Vestnik MGOU. Ser.: "Pedagogika". 2011, No. 3, pp. 217-220.

4. Gaydukova G. N. Sotsiologicheskiy monitoring udovletvorennosti potrebiteley kachestvom obrazovatelnykh uslug. Sovremennye problemy nauki i obrazovaniya. 2013, No. 1, pp. 463.

5. Divjak M., Rupel V. P., Lešnik K. M. The impact of study attitudes and study behaviour on satisfaction of online students with the implementation of online study programmes. Educational Media International. 2018, Vol. 55, Iss. 3, pp. 287-300. DOI: https://doi.org/10.1080/09523987.2018.1512450.

6. Machado E. A., Afonso L. E. Academic performance of students on the grounds of their satisfaction with distance education. International Journal of Innovation and Learning (IJIL). 2018, Vol. 23, No. 2. DOI: https://doi.org/10.1504/IJIL.2018.089616.

7. Barak M., Hussein-Farraj R., Dori Y. J. On-campus or online: examining self-regulation and cognitive transfer skills in different learning settings. International Journal of Educational Technology in Higher Education. 2016. DOI: https://doi.org/10.1186/s41239016-0035-9.

8. Hartnett M., St. George A. \& Dron J. Examining motivation in online distance learning environments: Complex, multifaceted and situation-dependent. The International Review of Research in Open and Distributed Learning. 2011, Vol. 12, No. 6, pp. 20-38.

9. Bekele T. A. Motivation and satisfaction in internet-supported learning environments: A review. Educational Technology \& Society. 2010, Vol. 13, Iss. 2, pp. 116-127.

10. McCombs B. L., Vakili D. A learner-centered framework for e-learning. Teachers College Record. 2005. Vol. 107, No. 8, pp. 1582-1600. 
11. Schunk D. H., Pintrich P. R., Meece J. L. Motivation in education. 3rd ed. Upper Saddle River, NJ: Pearson Merrill Prentice Hall, 2008.

12. Eom S. B., Ashill N. The Determinants of Students' Perceived Learning Outcomes and Satisfaction in University Online Education: An Update. Decision Sciences Journal of Innovative Education. 2016, Vol. 14, Iss. 2, pp. 185-215. DOI: https://doi.org/10.1111/ dsji.12097.

13. Ababkov Yu. N., Ababkov M. Yu. Marketingovye issledovaniya potrebiteley obrazovatelnykh uslug. Teoriya i praktika servisa: ekonomika, sotsialnaya sfera, tekhnologii. 2010, No. 2(4), pp. 96-102.

\section{Интернет-журнал}

«Проблемы современного образования»

\section{0, № 5}

Статья поступила В редакцию 21.02.2020

The article was received on 21.02.2020 